\title{
Aquatic
} botany

\section{Physiological effects of short-term salinity changes on Ruppia maritima}

\author{
Lesley R. Murphy ${ }^{b}$, Stephen T. Kinsey ${ }^{a, b}$, Michael J. Durako ${ }^{a, b, *}$ \\ a Center for Marine Science, University of North Carolina at Wilmington, Wilmington, NC 28409, USA \\ ${ }^{\mathrm{b}}$ Department of Biological Sciences, Washington State University, Pullman, WA 99164-4238, USA
}

Received 20 June 2001; received in revised form 9 October 2002; accepted 8 December 2002

\begin{abstract}
Changes in Ruppia maritima L. leaf-tissue osmolality, compatible solute synthesis in leaf tissues, and maximum effective quantum yield in response to short-term changes in salinity were investigated. Plants cultured at $20 \% \mathrm{~S}$ were exposed to $0 \% \circ \mathrm{S}, 10 \%_{\circ} \mathrm{S}$ (half-ambient), 20\%o S (ambient), and $40 \%$ S (twice-ambient) salinities. Total and non-vacuolar leaf osmolality for cultured plants significantly decreased (total: from $1464 \pm 266$ to $712 \pm 210 \mathrm{mmol} \mathrm{kg}^{-1}$; non-vacuolar: from $880 \pm 108$ to $257 \pm 80 \mathrm{mmol} \mathrm{kg}^{-1}$ ) or increased (total: from 1464 to $2532 \pm 673 \mathrm{mmol} \mathrm{kg}^{-1}$, non-vacuolar from 880 to $1168 \pm 15 \mathrm{mmol} \mathrm{kg}^{-1}$ ), within $1 \mathrm{~min}$ of exposure to 0 and $40 \%$ o S, respectively. After the initial rapid change in leaf osmolality, values were relatively constant for the first $180 \mathrm{~min}$ of exposure. Osmolality then changed again over the period from 1 to 2 days post-treatment with values again increasing $\left(40 \%\right.$ o S: total $=3152 \pm 335 \mathrm{mmol} \mathrm{kg}-1$, non-vacuolar $\left.=1967 \pm 103 \mathrm{mmol} \mathrm{kg}^{-1}\right)$ or decreasing $\left(0 \%\right.$ o S: total $=357 \pm 46 \mathrm{mmol} \mathrm{kg}^{-1}$, non-vacuolar $\left.=74 \pm 32 \mathrm{mmol} \mathrm{kg}^{-1}\right)$ with salinity. Soluble and total carbohydrates in leaf tissues responded differently to changing salinity. Total carbohydrates decreased by $65 \%$, while soluble levels increased by $34 \%$, in high salinity. Total and soluble proline levels increased (63 and 18\%, respectively), and decreased ( -36 and $-20 \%$ for $10 \%$ S; -72 and $-32 \%$ for $0 \%$ S , respectively), with salinity. These results suggest that both proline and soluble carbohydrates act as compatible solutes. Maximum quantum yields $\left(F_{\mathrm{v}} / F_{\mathrm{m}}\right)$ were measured over a $48 \mathrm{~h}$ period in response to changes in medium salinity and inorganic carbon (ambient and $\sim 2.0 \mathrm{mM}$ bicarbonate-equilibrium treatments). $F_{\mathrm{v}} / F_{\mathrm{m}}$ exhibited significant variation in response to salinity, bicarbonate-level and time as main effects, with significant interactions. Quantum yields were lowest in the 0 and $40 \%$ o $\mathrm{S}$ treatments; the 10 and $20 \%$ o S treatments had significantly higher quantum yields. These short-term responses indicated that both increases and reductions of external ion concentrations are initially stressful for $R$. maritima, but that it can physiologically adjust after several days. (C) 2003 Elsevier Science B.V. All rights reserved.
\end{abstract}

Keywords: Ruppia maritima; Osmolality; Compatible solutes; Bicarbonate; Photosynthesis

\footnotetext{
* Corresponding author. Tel.: +1-910-962-2372; fax: +1-910-962-2410.

E-mail address: durakom@uncwil.edu (M.J. Durako).
} 


\section{Introduction}

Salinity is one of the most critical environmental factors determining the structure of estuarine submerged angiosperm communities, with extreme salinity fluctuations resulting in lower biomass of plants and animals (Montague and Ley, 1993). Most studies on salinity-tolerance of submerged angiosperms have dealt with long-term effects and the parameters investigated have been mortality, ion accumulation, gross morphological parameters, or community structure (Dunton, 1990; Adams et al., 1992; Montague and Ley, 1993). Rapid salinity fluctuations can occur during intrusion of oceanic waters into coastal rivers and bays or from freshwater releases from spillways or water control structures (Kantrud, 1991). Rapid changes in salinity result in stress and mortality of submerged angiosperms, but little is known about how short-term salinity fluctuations affect photosynthesis or the physiological costs to the plant in terms of metabolite production (Tyerman, 1982; Tyerman et al., 1984).

Ruppia maritima L. (Widgeon Grass) has the widest known salinity tolerance of any submerged angiosperm (Kantrud, 1991). Bird et al. (1993) found that $R$. maritima from North Carolina could be maintained indefinitely in $0 \%$ S cultures; maximum reported salinity tolerance values range from approximately 160-390\%o S (Bourn, 1935; McMillan and Moseley, 1967; Kantrud, 1991; Bonis et al., 1993). One of the reasons $R$. maritima can survive such a wide range of salinities is its ability to osmoregulate (Kantrud, 1991).

Because submerged angiosperms have no salt-secreting glands and absorption of ions is through their leaves, they apparently osmoregulate through epidermal cells (Jagels, 1973). Submerged angiosperms and macroalgae may actively transport sodium, potassium, and chloride ions into channels associated with invaginated plasmalemmas containing numerous mitochondria (Jagels, 1973; Jagels, 1983; Jagels and Barnabas, 1989; Lee and Liu, 1999). There may also be active exclusion of salt by an ATP-requiring ion transport mechanism (Jagels, 1973). This exchange of ions allows for the maintenance of stable membrane potentials (Fernandez et al., 1999). However, ion accumulation is only beneficial for initial osmolarity adjustments and it may be insufficient, and energetically costly (if requiring constant ATP input), if the salinity stress is not removed. During longer periods of salinity stress, halophytes usually accumulate organic solutes within cells in order to maintain or restore turgor (Wyn Jones and Gorham, 1983). These so-called compatible solutes are non-inhibitory substances accumulated in cell cytoplasm in response to low external water potentials. $R$. maritima accumulates proline as its main osmolyte in response to increasing salinity (Stewart and Lee, 1974; Brock, 1981; Adams and Bate, 1994). Proline levels have equaled fifty percent of the solute concentration of the external habitat (Brock, 1981).

Changes in salinity may also affect photosynthetic rates in submerged angiosperms. Photosynthetic rates of $R$. maritima, as measured by oxygen evolution, increase from a low at $0 \% \circ \mathrm{S}$ to higher rates at 17.5 and 35\% (Lazar and Dawes, 1991). Koch and Dawes (1991) compared populations of $R$. maritima, from North Carolina and Florida, and found that plants from North Carolina had lower photosynthetic rates at all salinity treatments $(10,20$, and 30\%o), with the lowest photosynthetic rates at 30\%o S. This indicates that populations of $R$. maritima may display phenotypic, if not genotypic, variations. Hellblom and Bjork (1999) examined the role of inorganic carbon (Ci) and salinity on photosynthesis of Zostera marina. They found that that the decrease in photosynthesis observed in diluted seawater 
medium was mainly due to a decrease in the bicarbonate content of the medium rather than to reduced salinities.

To explore the temporal and directional response patterns of short-term salinity stress in $R$. maritima, three techniques were used in this study. First, leaf-tissue osmolality was measured in a short-time series to determine immediate effects. Measurements were taken on both fresh and frozen tissues so data reflect non-vacuolar (including cytoplasmic, lacunae, and intercellular) ions and total ion concentrations, respectively. The second technique used ${ }^{1} \mathrm{H}$ nuclear magnetic resonance (NMR) to identify and quantify compatible solutes in leaf tissue. NMR is a non-invasive technique that can be used to determine solute contents and concentrations within cells (Ratcliffe, 1994). The benefit of using NMR is that both soluble and insoluble molecules can be identified and analyzed. Here, cytoplasmic and total solutes were measured by analyzing tissues in vivo and by analyzing perchloric acid extracts, respectively. Finally, changes in maximum quantum yield were measured in response to salinity variations using pulse amplitude modulated (PAM) fluorometry. This fluorometric technique has recently been used to measure photosynthetic responses to variation in salinity in the seagrass Z. marina (Kamermans et al., 1999). To clarify the relationship between salinity and bicarbonate effects on photosynthesis in $R$. maritima, we conducted experimental salinity treatment series with, and without, establishing bicarbonate equilibrium.

\section{Materials and methods}

\subsection{Experimental material and conditions}

One-year old clonal cultures of $R$. maritima from Madeira Bay, in Florida Bay, USA $\left(25^{\circ} 15^{\prime} \mathrm{N}, 80^{\circ} 70^{\prime} \mathrm{W}\right)$ were used as experimental material as described by Koch and Durako (1991). Plants were cultured in liquid media containing 20\%o S Instant Ocean ${ }^{\circledR}$ (Aquarium Systems, Ohio, USA), 0.5 Murashige and Skoog Basal Salt mixture (M-5524, Sigma, Missouri, USA), $1 \%$ (w/v) sucrose, $10 \mathrm{mg}^{-1} 2 \mathrm{iP}$ (D-8532, Sigma) at $\mathrm{pH} 5.7$ under a 14:10 h L:D photoperiod with an average photosynthetic photon flux density (PPFD) of $140 \pm 25 \mu \mathrm{mol} \mathrm{m}{ }^{-2} \mathrm{~s}^{-1}$. At least 1 week prior to experimental use, plants were transferred to media containing only $20 \%$ o S Instant Ocean at $\mathrm{pH} 8.1$ to convert plants to autotrophic carbon metabolism (Ailstock et al., 1991).

$20 \%$ o $\mathrm{S}$ was considered the ambient salinity condition as this is a representative salinity for estuarine environments and is within the optimal range of salinities for R. maritima (Kantrud, 1991). Treatment salinities were made using Instant Ocean ${ }^{\circledR}$ diluted with deionized water and included $0 \%$ S (deionized water), half-ambient $(10 \% \circ \mathrm{S})$, ambient, and twice-ambient $(40 \%$ S $)$ salinities all at $\mathrm{pH} 8.1$.

\subsection{Determination of leaf-tissue osmolality}

Leaf-tissue osmolality was measured using a Wescor Vapor Pressure Osmometer 5520 (Logan, Utah). Measurements of leaf-tissue osmolality were made on four $20 \mathrm{~mm}$-long segments of leaf tissue. This amount of tissue was needed to cover the bottom of the osmometer sample holder. The osmometer was calibrated against 290 and $1000 \mathrm{mmol} \mathrm{kg}^{-1}$ 
standards. In this instrument, osmolality is measured based on the relationship between solute concentration and the vapor pressure of a solution. The protocol of Tyerman (1982) of setting a time delay for osmometer sample-chamber equilibration was used. In order to find a stable time delay, measurements were taken on fresh tissue every 2 min for $40 \mathrm{~min}$. After $20 \mathrm{~min}$, differences between measurements became insignificant (data not shown). For the determination of non-vacuolar versus total ion concentration and to assess various tissue-handling effects, tissues were blotted, crushed with a mortar and pestle, frozen at $-10{ }^{\circ} \mathrm{C}$ (for 2 and $3 \mathrm{~h}$ ) or frozen with liquid nitrogen. Paired $t$-tests were used to compare the initial and time delay measurements and ANOVA was used to assess variability among the handling treatments. Based on the preliminary results, the protocol that was adopted incorporated time-delayed (for $20 \mathrm{~min}$ ) measurements on fresh blotted tissue for non-vacuolar osmolality and instantaneous measurements on frozen $\left(2 \mathrm{~h}\right.$ at $\left.-10^{\circ} \mathrm{C}\right)$ blotted tissue for total leaf osmolality values. Measurements were taken 1, 5, 10, 30, 60, 90, $180 \mathrm{~min}, 24$ and $48 \mathrm{~h}$ post-treatment with six replicates for each treatment series. Tyerman (1982) found that the leaf water potential was lower than the medium water potential and concluded that it could be due to evaporation of water from the tissue during handling. To reduce this effect, leaf tissues were cut with the tissue fully submerged in the treatment media and handling time minimized.

\subsection{Determination of leaf compatible solute concentrations}

R. maritima leaf tissue was analyzed by ${ }^{1} \mathrm{H}$ NMR. Both in vivo leaves, to determine soluble molecules, and perchloric acid extracts of leaves, to determine combined soluble and insoluble molecules were measured. In vivo measurements were taken on 15-20, 2 cm-long leaf segments in approximately $0.5 \mathrm{ml}$ of experimental medium. This procedure measures water-soluble molecules. To estimate total intracellular-solute concentrations, leaf tissue was homogenized in $7 \%$ perchloric acid ( $4 \mathrm{ml}$ of perchloric acid per $\mathrm{g}$ tissue), centrifuged at $10,000 \times g$, and the supernatant was decanted and neutralized to $\mathrm{pH} 6.5$ with $3 \mathrm{M} \mathrm{KOH}$. Neutralized extracts were lyopholized, rehydrated in $0.5 \mathrm{ml} \mathrm{D}_{2} \mathrm{O}$ and analyzed using NMR. This procedure measures water-soluble and insoluble molecules. Perchloric acid extracts were prepared from the same plants that were used for the in vivo measurements. Additional samples were spiked with $10 \mathrm{mM}$ proline and alanine to verify chemical shifts in the NMR spectra and to approximate proline concentrations. Integrals were corrected for wet weight and receiver gain; for every one integral change, there was a change of $1.68 \mathrm{mM}$ proline $\mathrm{g}^{-1}$ fresh weight. For the $40 \% \mathrm{~S}$ treatment, with values that increased over the course of the experiment by approximately 0.5 integral, this would mean an increase of $0.84 \mathrm{mM}$ proline $\mathrm{g}^{-1}$ fresh weight.

${ }^{1} \mathrm{H}$ NMR spectra were obtained using a Bruker 400 DMX spectrometer operating at $400 \mathrm{MHz}$. Before starting scans, the spectrometer was shimmed on the water signal to obtain a homogeneous field. The water resonance was suppressed using a 10 s selective pre-saturation pulse. This was necessary due to the high concentration of water $(55 \mathrm{M})$ as compared to the micromolar concentrations of the molecules of interest. The excitatory radiofrequency pulse width of 11 microseconds corresponded to a $90^{\circ}$ tip angle with a sweep width of $10 \mathrm{kHz}$. One hundred twenty-eight scans were taken for a total time of $12 \mathrm{~min}, 15 \mathrm{~s}$ per spectrum. Fourier transformations converted data to spectra and peaks were 
analyzed by taking area integrals with a standard of an ambient pre-treatment proline peak. Data were normalized for differences in receiver gain, wet weight, and to the mean of the proline pre-treatment peaks. Because of analytical limitations, the NMR measurements were performed on a longer time series of pre-treatment, initial ( $30 \mathrm{~min}$ to $1 \mathrm{~h}$ post-treatment), and 2, 6, and 9 days post-treatment.

\subsection{Determination of leaffluorescence}

Leaf fluorescence measurements were made using a Mini-PAM fluorometer (Walz, Germany). Fluorescence was determined on the middle of blades of whole plants using a dark-clip (DLC-8, modified to minimize boundary layer restrictions as described by Beer et al., 1998) to ensure constant distance between the optical fiber and leaf. The plant material being measured was subjected to a pulse of saturating light and two fluorescence measurements were made; one before $\left(F_{\mathrm{o}}\right)$ and one during $\left(F_{\mathrm{m}}\right)$ the pulse. Maximum quantum yield was calculated as $F_{\mathrm{v}} / F_{\mathrm{m}}$ (where $F_{\mathrm{v}}=F_{\mathrm{m}}-F_{\mathrm{o}}$ ) using dark-acclimated leaves, which allows for all of the reaction centers to open and all primary electron acceptors to be oxidized (Beer et al., 2001).

Preliminary repeated measures indicated no significant differences in the $F_{\mathrm{v}} / F_{\mathrm{m}}$ ratio between series of $5 \mathrm{~min}$ and a series of $10 \mathrm{~min}$ dark-acclimation intervals (data not shown). The first experimental treatment series consisted of 5 min dark-acclimation, measurement of fluorescence in ambient salinity, change in salinity $(0$, half-ambient, ambient, or twice-ambient), dark-acclimation, fluorescence measurement, return to ambient, dark-acclimation, and final fluorescence measurement. Because the initial 5 min treatmentinterval series did not exhibit significant changes in leaf fluorescence characteristics in response to salinity changes, a second time series was conducted to investigate effects over a longer time period without replacing the plants in the ambient salinity. In an attempt to correlate changes in maximum quantum yields with changes in salinity, a time series similar to that used in the previous osmolality experiment $(5,30,90,180 \mathrm{~min}$, 24 and $48 \mathrm{~h}$ ) was used. Maximum quantum yields were measured on six replicates for each treatment salinity. Initial (5, 30, and $90 \mathrm{~min}), 24$ and $48 \mathrm{~h}$ measurements were taken early in the day (between 8 and 10 a.m.) to reduce variation due to diurnal rhythms. Modified dark-clips (described previously) were used for dark-acclimation of leaves; the rest of the plant was exposed to photosynthetic photon flux density (PPFD) of approximately $500 \mu \mathrm{mol} \mathrm{m}^{-2} \mathrm{~s}^{-1}$. This PPFD was found to be a saturating $\left(P_{\max }\right)$ irradiance through preliminary photosynthesis versus irradiance measurements of oxygen evolution using a Hansatech oxygen electrode system (data not shown) and was in agreement with published data (Koch and Dawes, 1991).

Because of previous suggestions that reductions in photosynthesis with reduced salinities may simply be due to reduced bicarbonate levels (Hellblom and Bjork, 1999), we compared photosynthetic responses in synthetic seawater (Instant Ocean ${ }^{\circledR}$ ) diluted with deionized water (ambient bicarbonate) to those in synthetic seawater that was treated to establish bicarbonate-equilibrium. For the bicarbonate-equilibrium treatment, synthetic seawater was diluted in the same manner as previously described. The media were then stripped of all soluble carbon by reducing the $\mathrm{pH}$ to 2 and bubbling overnight with carbon-free air. After stripping, the media were brought back to $\mathrm{pH} 8.1$ with carbon-free $\mathrm{NaOH}$ and bubbled with 
air overnight to attain atmospheric equilibrium. Because the solubility of $\mathrm{HCO}_{3}{ }^{-}$is the same across salinities, media in equilibrium with the atmosphere contain the same concentrations of carbon dioxide and bicarbonate $\left(\sim 12 \mu \mathrm{M} \mathrm{CO}_{2}\right.$ and $\left.\sim 2.0 \mathrm{mM} \mathrm{HCO}_{3}{ }^{-}\right)$.

\subsection{Statistical analyses}

The effects of salinity treatment and time on the variability of the response parameters were assessed using regression analyses, one-way ANOVA (salinity or time), two-way ANOVA (salinity, time and salinity $\times$ time interactions), or three-way ANOVA (salinity, time, bicarbonate concentration, and interactions). All data were tested for normality and homogeneity of variances by the Kolmogorov-Smirnov test with Lilliefors' correction and the Levene Median test, respectively. If normality failed and homogeneity passed, transformations were attempted. If no transformations were successful in achieving normal distributions, then parametric analyses were performed to assess the effects of time and treatment on the raw data. If homogeneity of variances failed, data transformations were again attempted. If no transformations were successful, then non-parametric analyses (Kruskal-Wallis one-way ANOVA on ranks) were used to assess treatment effects. If significant differences were found among treatments, then Tukey's or Dunnett's tests were used to determine specific treatment differences in parametric and non-parametric tests, respectively. All statistics were calculated using SigmaStat 2.0 with significance determined at the $95 \%$ probability level $(P<0.05)$.

\section{Results}

\subsection{Changes in leaf-tissue osmolality}

Total leaf-tissue osmolality changed within 1 min of exposure to treatment media, then exhibited little change from 1 to $180 \mathrm{~min}$ (Fig. 1a). Total osmolality subsequently increased in all treatments from 1-day post-treatment to 2 days, except for the $0 \%$ o treatment, which exhibited decreased total osmolality over this time period. Total leaf osmolality values ranged from $293 \mathrm{mmol} \mathrm{kg}^{-1}$ (0\%, 2 days) to $3887 \mathrm{mmol} \mathrm{kg}^{-1}$ (40\%, $1 \mathrm{~min}$ ). All treatment values showed significant change with time when analyzed by regression of osmolality over the entire experimental period of 2 days (Table 1). Both salinity and time had significant main effects on total leaf osmolality, but there was also significant interaction. The 10 and $20 \%$ S treatments exhibited similar patterns of little short-term change, but a significant increase in total leaf osmolality at 2 days. The $40 \%$ o $\mathrm{S}$ treatment significantly increased in total leaf osmolality after $24 \mathrm{~h}$.

The patterns in non-vacuolar osmolality were similar to those of total leaf osmolality. Osmolality approached media values within $1 \mathrm{~min}$ of exposure (i.e. $1 \mathrm{~min}$ in treatment media and 20 min of time delay within the osmometer chamber), but the magnitude of the changes over the experimental time course were not as great (Fig. 1b). Treatment media osmolality values were $13.7,322,645$, and $1289 \mathrm{mmol} \mathrm{kg}^{-1}$, corresponding to $0,10,20$, and $40 \% \mathrm{~S}$, respectively. Regression slopes were significant for all non-vacuolar measurements, except for the $10 \%$ o $\mathrm{S}$ treatment, which did not change significantly with time. Salinity had a 

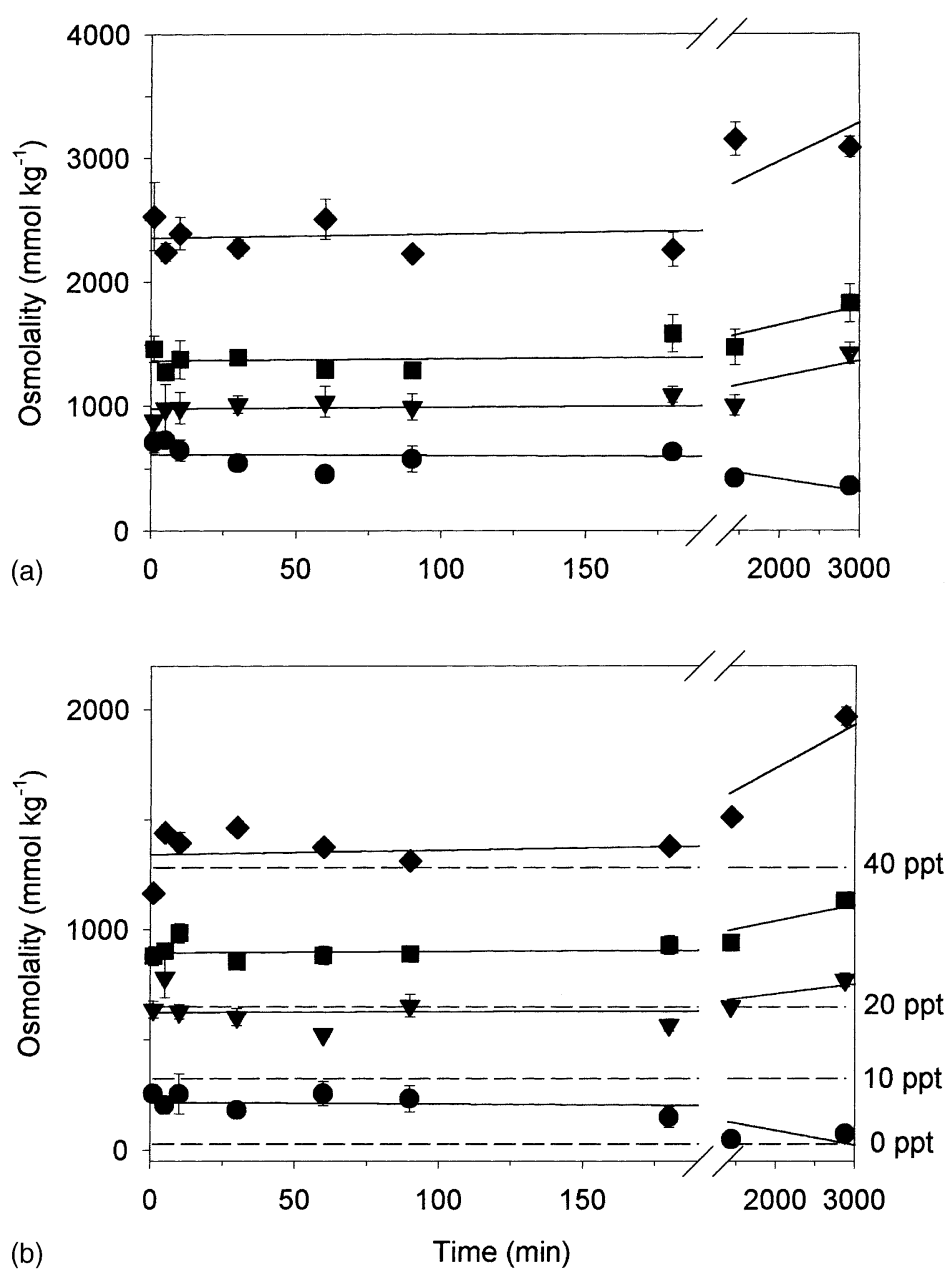

Fig. 1. R. maritima. Changes in (a) total leaf and (b) non-vacuolar osmolality in response to salinity over a 2 days period (mean \pm standard error, $n=6$ ). Salinity treatment media osmolalities, indicated by dashes, with values of $13.7,322,645$, and $1289 \mathrm{mmol} \mathrm{kg}^{-1}$ correspond to 0 (circles), 10 (squares), 20 (triangles), and 40 (diamonds) \%o $\mathrm{S}$, respectively.

significant effect on non-vacuolar osmolality $\left(H_{3 \mathrm{~d} . f .}=196.32, P<0.001\right)$, but changes over time were not significant $\left(H_{8 \text { d.f. }}=2.40, P=0.10\right)$.

\subsection{Changes in leaf compatible solute concentrations}

Based on published chemical shifts (Fan et al., 1986; Fan et al., 1993; Behar et al., 1983, http://www.bmrb.wisc.edu) and two-dimensional Cosy spectra run on perchloric extracts, the following chemical shifts were assigned to NMR spectra for metabolite comparisons. Alanine was assigned $1.47 \mathrm{ppm}$, proline $2.1 \mathrm{ppm}$, and carbohydrates (primarily sucrose 
Table 1

R. maritima; regression analysis of changes in total leaf and non-vacuolar tissue osmolality, over time, in plants placed in 0,10,20, and 40\%o salinity media and two-way ANOVA comparing variation in total leaf-tissue osmolality due to salinity and time

d.f. $F / H \quad P$

\section{Regression}

Total leaf

$\begin{array}{ccrc}0 \% \text { Salinity } & 1 & 9.5 & 0.018 \\ 10 \% \text { Salinity } & 1 & 18.4 & 0.004 \\ \text { 20\%o Salinity } & 1 & 14.4 & 0.007 \\ 40 \% \text { Salinity } & 1 & 19.9 & 0.003 \\ \text { on-vacuolar } & & & 0.008 \\ \text { 0\%० Salinity } & 1 & 13.2 & 0.159 \\ 10 \% \text { Salinity } & 1 & 2.5 & 0.003 \\ 20 \% \text { Salinity } & 1 & 19.4 & 0.001 \\ 40 \% \text { Salinity } & 1 & 28.9 & \end{array}$

Two-way ANOVA

Total leaf

Salinity

Time 8

$\begin{aligned} 564.9 & <0.001 \\ 5.6 & <0.001 \\ 4.1 & <0.001\end{aligned}$

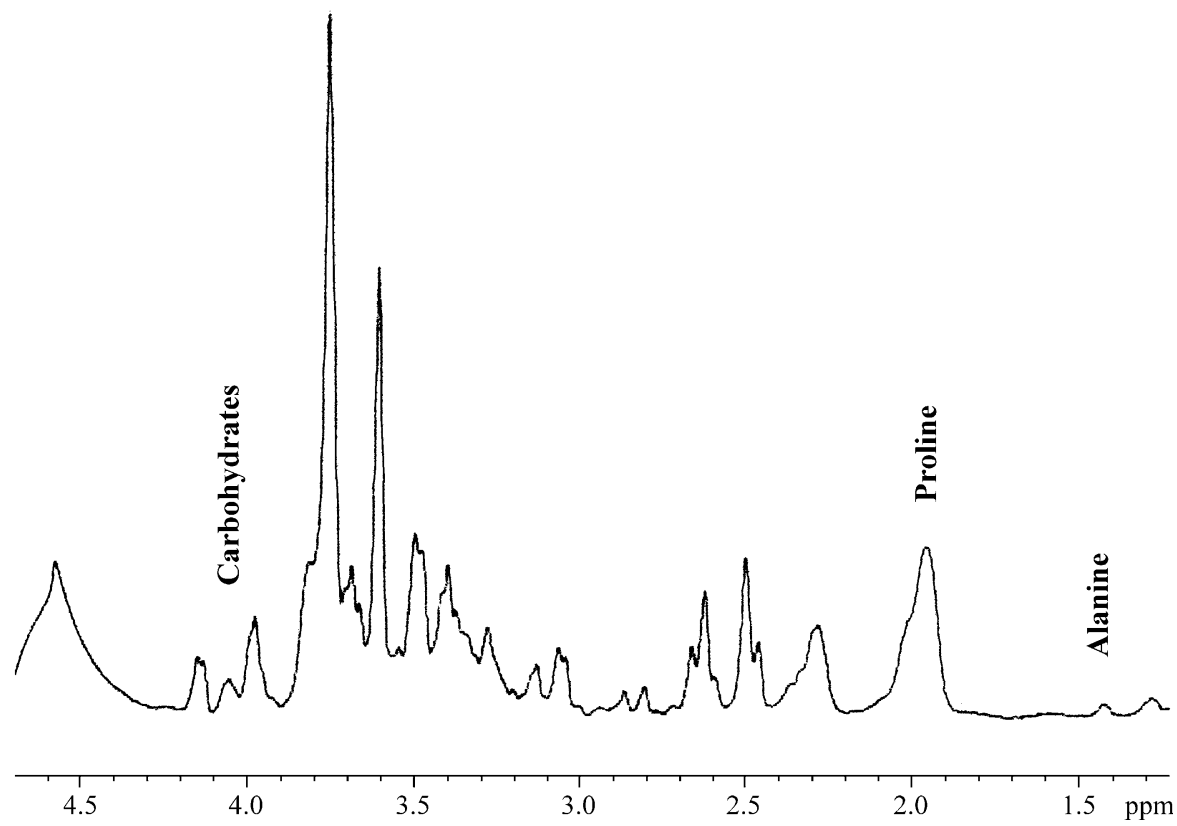

Fig. 2. R. maritima. NMR spectrum of a perchloric acid extract of a plant transferred from 20 to $40 \%$ S, after 6 days. 
and glucose), due to overlap of peaks, were assigned to the area between 3.8 and $4.2 \mathrm{ppm}$ (Fig. 2). Total proline levels in the $0 \% \mathrm{~S}$ treatment varied significantly over the 9 days experimental period, with values decreasing by $72 \%$ the first 6 days, but by day 9 increasing to above pre-treatment levels (Fig. 3a). After 9 days, proline levels in the plants in the 10\%o $\mathrm{S}$ treatment were significantly lower (36\%) than before treatment (Table 2). Proline levels in plants in $40 \%$ o $\mathrm{S}$ increased by $63 \%$ over the 9 days, while levels in $20 \%$ o S remained relatively constant. The perchloric acid extract data indicated that total proline levels were not significantly different among salinity treatments (Table 2). Total proline concentration
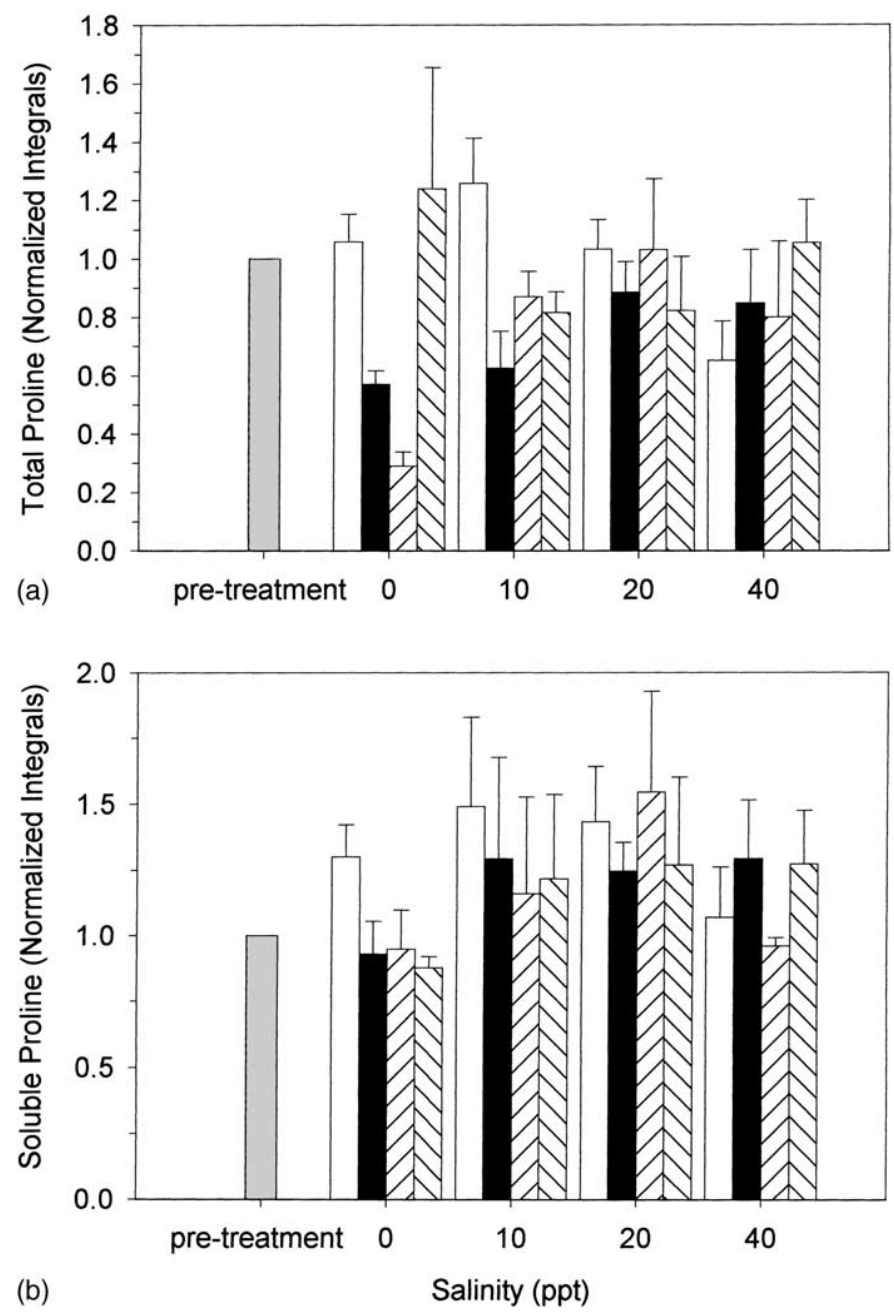

Fig. 3. R. maritima. Changes in (a) total and (b) soluble proline concentrations in leaf tissues in response to changes in salinity (mean \pm standard error, $n=6$ ). integrals are normalized by the mean of the pre-treatment proline peaks. Treatment symbols are: $(\square)$ pre-treatment; $(\square)$ initial; $(\square) 2$ days; ( $\square) 6$ days; $(\square) 9$ days. 
Table 2

R. maritima; two-way ANOVAs comparing variation in total proline and carbohydrate concentrations, measured as integrals from NMR spectra from perchloric acid extracts, analyzed over time and combined salinity treatments and one-way ANOVAs comparing variation in total and soluble proline and carbohydrates, measured as integrals from perchloric acid extracts and in vivo NMR spectra, analyzed over time at individual salinities

\begin{tabular}{|c|c|c|c|}
\hline & d.f. & $F / H$ & $P$ \\
\hline \multicolumn{4}{|l|}{ Two-way ANOVA } \\
\hline \multicolumn{4}{|l|}{ Total proline } \\
\hline Salinity & 3 & 2.6 & 0.811 \\
\hline Time & 3 & 3.3 & 0.023 \\
\hline Salinity $\times$ time & 9 & 1.8 & 0.106 \\
\hline \multicolumn{4}{|l|}{ Total carbohydrates } \\
\hline Salinity & 3 & 13.9 & $<0.001$ \\
\hline Time & 3 & 0.6 & 0.605 \\
\hline Salinity $\times$ time & 9 & 3.3 & 0.002 \\
\hline \multicolumn{4}{|l|}{ One-way ANOVA } \\
\hline \multicolumn{4}{|l|}{ Total proline } \\
\hline $0 \%$ Salinity & 3 & 12.3 & 0.007 \\
\hline $10 \%$ Salinity & 3 & 5.4 & 0.007 \\
\hline $20 \% o$ Salinity & 3 & 0.4 & 0.762 \\
\hline $40 \%$ o Salinity & 3 & 0.8 & 0.515 \\
\hline \multicolumn{4}{|l|}{ Soluble proline } \\
\hline $0 \%$ o Salinity & 3 & 2.7 & 0.075 \\
\hline $10 \%$ o Salinity & 3 & 0.7 & 0.559 \\
\hline $20 \% o$ Salinity & 3 & 0.2 & 0.857 \\
\hline $40 \%$ o Salinity & 3 & 0.7 & 0.560 \\
\hline \multicolumn{4}{|l|}{ Total carbohydrates } \\
\hline $0 \%$ Salinity & 3 & 3.7 & 0.028 \\
\hline $10 \%$ Salinity & 3 & 1.2 & 0.321 \\
\hline $20 \%$ o Salinity & 3 & 2.7 & 0.071 \\
\hline $40 \%$ Salinity & 3 & 1.0 & 0.428 \\
\hline \multicolumn{4}{|c|}{ Soluble carbohydrates } \\
\hline $0 \%$ Salinity & 3 & 2.4 & 0.098 \\
\hline $10 \%$ o Salinity & 3 & 0.7 & 0.588 \\
\hline $20 \%$ o Salinity & 3 & 0.6 & 0.604 \\
\hline $40 \%$ o Salinity & 3 & 2.0 & 0.151 \\
\hline
\end{tabular}

did change significantly with time when all salinity treatment data were pooled, however, within salinity treatments, the 20 and $40 \%$ o S treatment values did not vary significantly with time. In vivo data could only be analyzed within treatments, to look at time, because separate integrations were done for each salinity level. Thus, the absolute integral values among different treatments are not directly comparable for both proline and carbohydrates. In contrast, total proline and carbohydrate levels were based on a single integral and thus relative levels are comparable. Soluble proline levels decreased in the 0 and $10 \%$ S treatments ( 32 and $20 \%$, respectively), increased by $18 \%$ in the $40 \%$ o S treatment, and remained relatively constant in the $20 \%$ o S treatment (Fig. 3b). 

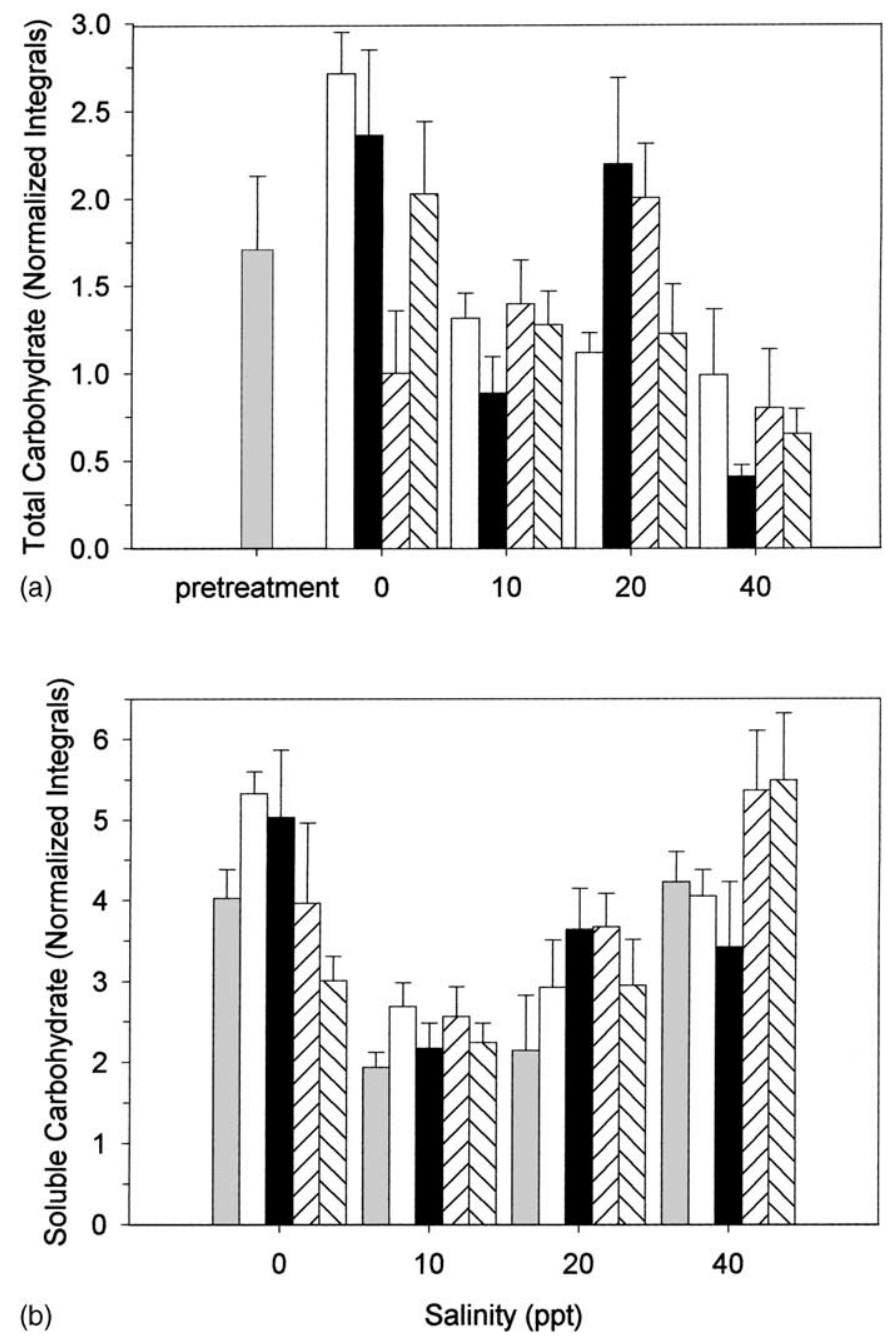

Fig. 4. R. maritima. Changes in (a) total and (b) soluble carbohydrate concentrations in leaf tissues in response to changes in salinity (mean \pm standard error, $n=6$ ). Integrals are normalized by the mean of the pre-treatment proline peaks for relative comparisons of the magnitude of changes in proline and carbohydrate levels. Soluble carbohydrate integrals are normalized within each treatment because separate pre-treatment integrations were done for each salinity level. Treatment symbols as in Fig. 1.

Carbohydrate levels in the $40 \%$ S treatment decreased by $65 \%$ over the 9 days treatment period when extracts were analyzed, but increased by $34 \%$ for the in vivo measurements (Fig. 4a and b). This indicates a decrease in the total amount of carbohydrates in response to an increase in salinity, but a mobilization of remaining carbohydrates into the cytoplasm, for osmoregulation. At $0 \% \mathrm{~S}$, values of total carbohydrates showed the same pattern as proline concentrations; decreasing by $63 \%$ for the first 6 days, but increasing 
by $200 \%$ by day 9 , while soluble levels decreased by $43 \%$. In the $10 \%$ o S treatment, both total and soluble levels of carbohydrates exhibited little variation. Total and soluble carbohydrate levels were more variable in the $20 \%$ S treatment. Total carbohydrate values varied significantly among treatments, but not with time (Table 2). However, the 10, 20, and $40 \%$ S total carbohydrate concentrations did not show significant differences over time in the individual treatments. There were also no significant differences across time in the soluble carbohydrate values. This lack of statistical significance in the compatible solute data reflects high variability attributable to both integral selection and plant-to-plant variation.
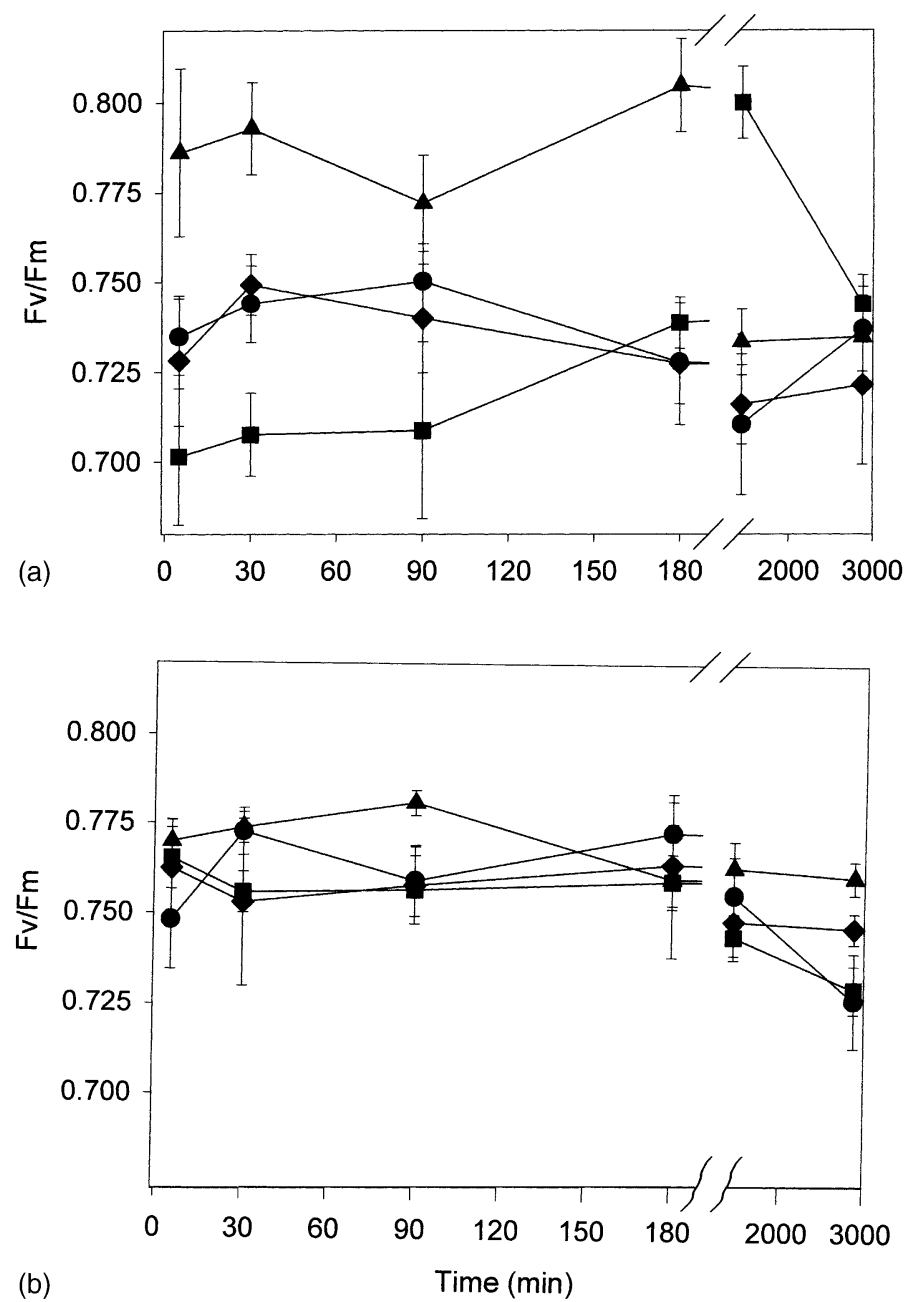

Fig. 5. R. maritima. Maximum quantum yields of 5 min dark-acclimated leaves in (a) ambient bicarbonate and (b) bicarbonate-equilibrium media in response to changes in salinity (mean \pm standard error, $n=6$ ). Treatment symbols as in Fig. 1. 
Table 3

R. maritima; Three-way ANOVAs comparing variation in maximum quantum yields among salinity, time, and bicarbonate treatments

\begin{tabular}{lrrr}
\hline & d.f. & $F$ & $P$ \\
\hline Three-way ANOVA & & & \\
Maximum quantum yield & & & $<0.001$ \\
Salinity & 3 & 12.4 & 0.029 \\
Time & 5 & 2.5 & $<0.001$ \\
Bicarbonate & 1 & 18.6 & 0.012 \\
Salinity $\times$ time & 15 & 2.1 & 0.038 \\
Salinity $\times$ bicarbonate & 3 & 2.9 & 0.826 \\
Time $\times$ bicarbonate & 5 & 0.4 & $<0.001$ \\
Salinity $\times$ time $\times$ bicarbonate & 15 & 3.5 & \\
\end{tabular}

Total alanine levels did not change significantly in response to salinity $(P=0.272)$ or time $(P=0.950)$. Additionally, changes in alanine concentration were much smaller in magnitude than those observed in proline levels (data not shown).

\subsection{Changes in leaf tissue fluorescence}

Dark-acclimated plants in the $20 \% \mathrm{~S}$ ambient-bicarbonate treatment exhibited the highest initial maximum quantum yields $\left(F_{\mathrm{v}} / F_{\mathrm{m}}\right.$, Fig. $\left.5 \mathrm{a}\right)$. After $24 \mathrm{~h}, F_{\mathrm{v}} / F_{\mathrm{m}}$ fell but were stable to $48 \mathrm{~h}$. Maximum quantum yields of plants in the $10 \%$ o $\mathrm{S}$ treatment were initially lower than the other treatments but rose to end with the highest values after 2 days. Surprisingly, the 0 and $40 \%$ S treatments had stable and similar $F_{\mathrm{v}} / F_{\mathrm{m}}$ throughout the 2 days that were generally lower than those of the $20 \%$ o $\mathrm{S}$ treatment. All treatments had similar $F_{\mathrm{v}} / F_{\mathrm{m}}$ values after 2 days.

Variability in $F_{\mathrm{v}} / F_{\mathrm{m}}$ across salinities and time was reduced in the bicarbonate-equilibrium treatments. Plants in the $20 \%$ S bicarbonate-equilibrium treatment had slightly higher initial $F_{\mathrm{V}} / F_{\mathrm{m}}$, but it dropped between 90 and $180 \mathrm{~min}$, and stabilized for the remaining time in treatment (Fig. 5b). Maximum quantum yield of the $40 \%$ o $\mathrm{S}$ treatment displayed the least temporal variability with values lower than the $20 \%$ S treatment, except for the 180 min value. The $10 \%$ o S treatment $F_{\mathrm{v}} / F_{\mathrm{m}}$ values were initially similar to the $40 \%$ o $\mathrm{S}$ treatment, but they steadily dropped from $180 \mathrm{~min}$ to $48 \mathrm{~h}$ after treatment. The $F_{\mathrm{v}} / F_{\mathrm{m}}$ values of the $0 \%$ S treatment were initially the lowest, fluctuated the first day, but also steadily dropped from $180 \mathrm{~min}$ to $48 \mathrm{~h}$ to end up with the lowest quantum yields. Although the three treatment variables (salinity, time, and bicarbonate levels) exhibited significant main effects on $F_{\mathrm{v}} / F_{\mathrm{m}}$ for $R$. maritima (Table 3), there were significant interactions between salinity and time, between salinity and bicarbonate, and among all three variables, but not between bicarbonate and time (Table 3 ).

\section{Discussion}

R. maritima exhibited a two temporal-scale pattern in total leaf osmolality in response changes in external salinity. There was an initial, almost immediate, response that followed 
the direction of the salinity treatment. This suggests that non-vacuolar ion changes or changes in leaf water content occur rapidly in this species. After the initial rapid change, osmolality remained stable until after 1-2 days in the salinity treatment, when there was a second shift, again in the direction of the new treatment medium. This longer-term response may be due to initiation of cellular infrastructure necessary for compatible solute synthesis, a frequently observed long-term response to salinity change in halophytes (Flowers et al., 1977). The significant short-term effect on non-vacuolar and total leaf osmolality did not increase or decrease over the first $180 \mathrm{~min}$ for non-vacuolar osmolality. This suggests changes in salinity affect cytoplasmic and intercellular solute concentrations more rapidly than in the vacuoles. Tyerman et al. (1984) found short-term increases in cell osmolality with increasing salinity that correlated with increases in sodium, potassium and chloride ions. Meyer et al. (1989) compared longer-term osmotic responses of two species of grasses to different salinities after 4 and 8 weeks exposure; osmolality increased with salinity, but the data for the two exposure periods were almost identical. This implies that once the osmotic potential of the plant has adjusted to the external medium, it stabilizes. Up to $75 \%$ of the change in osmolality, in response to long-term salinity stress, can be due to the synthesis of compatible solutes like proline (Brown and Hellebust, 1978). Accumulation or depletion of proline in $R$. maritima began within 2 days after salinity treatment and concentrations continued to change throughout treatment period. This trend was more pronounced in the total solute (perchloric acid extract) NMR spectra. These data agree with the notion that significant proline accumulation occurs after a time lag, and that when exposed to lower salinities, proline levels are reduced. Surprisingly, the proline levels in the $0 \%$ o $\mathrm{S}$ treatment, after declining over 6 days of treatment, rebounded to starting levels by day 9 . This pattern was also seen in the carbohydrate NMR spectra, suggesting a change in metabolism or leaf water content in response to this low-salinity treatment. The differing temporal patterns between extract and in vivo sugar measurements indicate that although the total levels of sugars were decreasing in the higher salinities, the available sugars were increasingly being converted to a soluble form for osmoregulation.

Proline concentrations in $R$. maritima exposed to high salinity were almost twice as high as most values reported in the literature (Stewart and Lee, 1974; Brock, 1981). However, increases in salinity may produce osmolyte concentrations of up to $4.0 \mathrm{M}$ (Flowers et al., 1977); $1.5 \mathrm{~mol}$ proline $\mathrm{kg}^{-1}$ water has an osmolality of $1.64 \mathrm{osmol} \mathrm{kg} \mathrm{g}^{-1}$ (Brown and Hellebust, 1978) which is in the range seen in the osmolality data for $R$. maritima in this study. Brock (1981) reported low and moderate salinity osmolality values very similar to those of our 0 and $20 \%$ S treatments. However, the highest osmolality values measured by Brock (1981), the $38 \%$ S treatment, were much lower than those found in this study's $40 \%$ S treatment $\left(1541 \mathrm{mmol} \mathrm{kg}^{-1}\right.$ versus $\left.>3000 \mathrm{mmol} \mathrm{kg}^{-1}\right)$. These differences may be due to different methodologies and growth conditions among studies, but they may also indicate there are ecotypic differences in salinity responses among populations and species of Ruppia.

Exposure of $R$. maritima that had been acclimated in $20 \% \mathrm{~S}$ to 0,10 and $40 \% \mathrm{~S}$ had an almost immediate effect of reducing maximum quantum yields. This effect was more pronounced in the first $24 \mathrm{~h}$ after treatment, which may have been due to changes in ionic steady state, compatible solute synthesis, or water content of the leaf tissues. After $48 \mathrm{~h}$, quantum yields recovered in all but the $40 \% \mathrm{~S}$ treatment. This may indicate that the plants 
in high salinities were still not fully acclimated to this high salinity after 2 days. Some of the short-term variation across salinities may also have been due to varying bicarbonate concentrations, especially in the ambient-bicarbonate salinity treatments. In this regard, stabilizing the initial bicarbonate concentrations to $\sim 2.0 \mathrm{mM}$, by bubbling air and controlling $\mathrm{pH}$, in the bicarbonate-equilibrium treatments had the effect of moderating the variability in photosynthetic efficiency across salinity treatments. Hellblom and Bjork (1999) found reductions in photosynthesis of Z. marina when bicarbonate was diluted, both through diluting salinity and at constant salinity over a range of bicarbonate. However, they did not observe a salinity effect when bicarbonate was kept constant $(2 \mathrm{mM}$ at $\mathrm{pH} 8.2)$. Photosynthesis was significantly depressed when salinity was reduced to $5 \%$ o $\mathrm{S}$ or lower with a concurrent reduction in inorganic carbon, and when salinity was kept at $33 \%$ o S and bicarbonate alone was diluted to $1 \mathrm{mM}$ or lower. A simple salinity-bicarbonate correlation was not evident in $R$. maritima; maximum quantum yields were significantly depressed in both the 0 and $40 \%$ S treatments (i.e. low and high bicarbonate). However, the convergence of photosynthetic responses from $24 \mathrm{~h}$ to 2 days in the ambient-bicarbonate treatments may reflect the re-establishment of air/media bicarbonate equilibrium.

Ruppia reportedly has the widest salinity tolerance of any genera of submerged angiosperm. However, the physiological responses observed in this study indicate this species may be stressed by both low and moderate salinities. Plants, having been grown and acclimated in $20 \%$ S , displayed the highest photosynthetic efficiency, and lowest amount of change in osmolality and solute concentrations in $20 \%$ S. In $10 \% \circ \mathrm{S}$, there was little change from the ambient conditions in most of the parameters measured, indicating the near absence of stress. However, in the 0 and $40 \%$ S treatments, there were significant changes in all parameters investigated. In the $40 \%$ o S treatment, plants showed an initial depression in photosynthesis and carbohydrate levels that eventually increased but remained lower than the control. This indicates some recovery from the initial ionic change, but a degree of persistent physiological stress. In the $0 \%$ o $\mathrm{S}$ treatment, there was again initial depression in all parameters but the plants recovered in photosynthetic efficiency after 2 days, and in solute concentrations after 6 days, with resulting levels being equal to or greater than the control. This recovery may reflect the non-obligatory halophytic nature of $R$. maritima, in that reductions in external ion concentrations are initially stressful, but after physiological adjustments the plants are able to overcome the stress and actually function more efficiently. Thus, this species may be more likely to disappear in areas that change from estuarine to marine, a finding that could have significant management implications with respect to issues related to freshwater inflow.

\section{Acknowledgements}

This research was partially funded by the University of Florida (Grant no. 5-50011) under prime contract \#C-E6612 from the South Florida Water Management District and by the University of North Carolina at Wilmington's Center for Marine Science Research summer grants. 2D Cosy NMR spectra, run on perchloric extracts, were provided by Justin Brown, The University of North Carolina at Wilmington. We thank Dr. G. Bowes and two anonymous reviewers for their editorial suggestions. 


\section{References}

Adams, J.B., Knoop, W.T., Bate, G.C., 1992. The distribution of estuarine macrophytes in relation to freshwater. Bot. Mar. 35, 215-226.

Adams, J.B., Bate, G.C., 1994. The ecological implications of tolerance to salinity by Ruppia cirrhosa (Petagna) Grande and Zostera capensis Setchell. Bot. Mar. 37, 449-456.

Ailstock, M.S., Fleming, W.J., Cooke, T.J., 1991. The characterization of axenic culture systems suitable for plant propagation and experimental studies of the submersed aquatic angiosperm Potamogeton pectinatus (sago pondweed). Estuaries 14, 57-64.

Beer, S., Vilenkin, B., Weil, A., Veste, M., Susel, L., Eshel, A., 1998. Measuring photosynthetic rates in seagrasses by pulse amplitude modulated (PAM) fluorescence. Mar. Ecol. Prog. Ser. 174, 293-300.

Beer, S., Björk, M., Gademann, R., Ralph, P., 2001. Measurements of photosynthetic rates in seagrasses. In: Short, F.T., Coles, R.G. (Eds.), Global Seagrass Research Methods. Elsevier, Amsterdam, pp. 183-198.

Bird, K.T., Cody, B.R., Jewett-Smith, J., Kane, M.E., 1993. Salinity effects on Ruppia maritima L. cultured in vitro. Bot. Mar. 36, 23-28.

Bonis, A., Gillas, P., van Wijck, C., Lepart, J., 1993. The effect of salinity on the reproduction of coastal submerged macrophytes in experimental communities. J. Veg. Sci. 4, 461-468.

Bourn, W.S., 1935. Sea-water tolerance of Ruppia maritima L. Contrib. Boyce Thompson Inst. 7, $249-255$.

Brock, M.A., 1981. Accumulation of proline in a submerged aquatic halophyte, Ruppia L. Oecologia 51, $217-219$.

Brown, L.M., Hellebust, J.A., 1978. Sorbitol and proline as intracellular osmotic solutes in the green algae, Stichococcus bacillaris. Can. J. Bot. 56, 676-679.

Dunton, K.H., 1990. Production ecology of Ruppia maritima L. S.1. and Halodule wrightii Aschers in two subtropical estuaries. J. Exp. Mar. Biol. Ecol. 143, 147-164.

Fan, T.W.M., Colmer, T.D., Lane, A.N., Higashi, R.M., 1993. Determination of metabolites by ${ }^{1} \mathrm{H}-\mathrm{NMR}$ assignments and GC: analysis for organic osmolytes in crude tissue extracts. Anal. Biochem. 214, 260-271.

Fernandez, F.A., Garcia-Sanchez, M.J., Felle, H.H., 1999. Physiological evidence for a proton pump and sodium exclusion mechanisms at the plasma membrane of the marine angiosperm Zostera marina L. J. Exp. Bot. 50, 1763-1768.

Flowers, T.J., Troke, P.K., Yeo, A.R., 1977. The mechanism of salt tolerance in halophytes. Annu. Rev. Plant Physiol. 28, 89-121.

Hellblom, F., Bjork, M., 1999. Photosynthetic resonses in Zostera marina to decreasing salinity, inorganic carbon content and osmolality. Aquat. Bot. 65, 97-104.

Jagels, R., 1973. Studies of a marine grass. Thalassia testudinum. Part I. Ultrastructure of the osmoregulatory leaf cells. Am. J. Bot. 60, 1003-1009.

Jagels, R., 1983. Further evidence for osmoregulation in epidermal leaf cells of seagrasses. Am. J. Bot. 70, 327-333.

Jagels, R., Barnabas, A., 1989. Variation in leaf ultrastructure of Ruppia maritima L. along a salinity gradient. Aquat. Bot. 33, 207-221.

Kamermans, P., Hemminga, M.A., de Jong, D.J., 1999. Significance of salinity and silicon levels for growth of a formerly estuarine eelgrass (Zostera marina) populations (Lake Grevelingen, The Netherlands). Mar. Biol. $133,527-539$.

Kantrud, H.A., 1991. Wigeongrass (Ruppia maritima L.): a literature review. US Fish Wildl. Serv., Fish. Wildl. Res. 10, 58.

Koch, E.W., Dawes, C.J., 1991. Ecotypic differentiation in populations of Ruppia maritima L. germinated from seeds and cultured under algae-free laboratory conditions. J. Exp. Mar. Biol. Ecol. 152, 145-159.

Koch, E.W., Durako, M.J., 1991. In vitro studies of the marine angiosperm Ruppia maritima: auxin and cytokinin effects on plant growth. Mar. Biol. 110, 1-6.

Lazar, A.C., Dawes, C.J., 1991. A seasonal study of the seagrass Ruppia maritima L. in Tampa Bay, Florida. Organic constituents and tolerances to salinity and temperature. Bot. Mar. 34, 265-269.

Lee, T.M., Liu, C.H., 1999. Correlation of decreased calcium contents with proline accumulation in the marine green macroalga Ulva fasciata exposed to elevated $\mathrm{NaCl}$ contents in seawater. J. Exp. Bot. 50, 1855-1862.

McMillan, C., Moseley, F.N., 1967. Salinity tolerances of five marine spermatophytes of Redfish Bay, Texas. Ecology 48, 503-506.

Meyer, M.J., Smith, M.A.L., Knight, S.L., 1989. Salinity effects on St. Augustine grass: a novel system to quantify stress response. J. Plant Nutr. 12, 893-908. 
Montague, C.L., Ley, J.A., 1993. A possible effect of salinity fluctuation on abundance of benthic vegetation and associated fauna in northeastern Florida Bay. Estuaries 16, 703-717.

Ratcliffe, R.G., 1994. In vivo NMR studies of higher plants and algae. In: Callow, J.A. (Ed.), Advances in Botanical Research, vol. 20. Academic press, London, pp. 43-123.

Stewart, G.R., Lee, J.A., 1974. The role of proline accumulation in halophytes. Planta 120, 279-289.

Tyerman, S.D., 1982. Water relations of seagrasses stationary volumetric elastic modules and osmotic pressure of the leaf cells of Halophila ovalis, Zostera capricorni, and Posidonia australis. Plant Physiol. 69, 957-965.

Tyerman, S.D., Hatcher, A.I., West, R.J., Larkum, A.W.D., 1984. Posidonia australis growing in altered salinities: leaf growth, regulation of turgor and the development of osmotic gradients. Aust. J. Plant Physiol. 11, 35-47.

Wyn Jones, R.G., Gorham, J., 1983. Osmoregulation. In: Lange, O.L., Nobel, P.S., Osmond, C.B., Ziegler, H. (Eds.), Encyclopedia of Plant Physiology, vol. 12C. Physiological Plant Ecology. Springer, Berlin, pp. 35-58. 